\title{
Article
}

\section{Developing Information Fluency in Introductory Biology Students in the Context of an Investigative Laboratory}

\author{
Gary J. Lindquester, Romi L. Burks, ${ }^{*}$ and Carolyn R. Jaslow
}

Department of Biology, Rhodes College, 2000 North Parkway, Memphis, TN 38112

Submitted July 7, 2004; Revised October 6, 2004; Accepted October 11, 2004

Monitoring Editor: Erin Dolan

\begin{abstract}
Students of biology must learn the scientific method for generating information in the field. Concurrently, they should learn how information is reported and accessed. We developed a progressive set of exercises for the undergraduate introductory biology laboratory that combine these objectives. Pre- and postassessments of approximately 100 students suggest that increases occurred, some statistically significant, in the number of students using various library-related resources, in the numbers and confidence level of students using various technologies, and in the numbers and confidence levels of students involved in various activities related to the scientific method. Following this course, students should be better prepared for more advanced and independent study.
\end{abstract}

Keywords: information fluency, information literacy, introductory biology laboratory, undergraduate, scientific method, pedagogy

\section{INTRODUCTION}

In recent years, introductory science laboratory courses at many colleges and universities have evolved from being a series of exercises designed simply to demonstrate scientific principles to being investigative experiments designed to engage students in the scientific method (National Research Council, 2002). Scientific educators advocate that student participation in the scientific method (i.e., following the steps from observation to hypothesis formulation to data analysis, conclusions, and presentation) at an earlier stage of the academic career provides more effective teaching and training of future scientists (Siebert and McIntosh, 2001). However, while using hands-on experimentation (laboratory research) to boost student interest and comprehension (Biological Science Curriculum Study, 1993), professors face the additional challenge of teaching students the information-gathering skills required of real-life researchers.

Students must learn to seek previously published information (library research), both to guide their hypothesis formulation and also to place their own results in context. In

DOI: $10.1187 /$ cbe.04-07-0046

*Present address: Department of Biology, Southwestern University, Georgetown, TX 78626.

Address correspondence to: Gary J. Lindquester (glindquester@ rhodes.edu). years past, students would consult abstracts, books, and journals within the physical confines of the library. With the advent of digital citation databases and electronically published journals, students are now likely to conduct much of their library research online. However, because most lack formal training in the nature of scientific information, many students possess insufficient skills to discriminate between valid and invalid electronic sources. As Lyman (2001) notes, "The Internet is now used as an information resource of first resort, including Web pages, Usenet, and electronic mail. The Web represents the end of authorship, because the Web erases the distinction between writing and publishing, thereby abandoning the quality control that makes printed information efficient, but it is more democratic because it lets the reader be the judge" (p. 30). Furthermore, "Unofficial documents used to be a private matter-like photo albums or letters that were occasionally archived and preserved in public institutions. But the network includes everything, public and private, true and false, good and bad" (p. 31).

With these statements, Lyman (2001) attracts our attention to a fundamental issue facing education. Previously, educators could direct students to written literature with some faith in the process of careful and informed peer review that preceded the publication. The scientific community relies on such peer review to provide validity to its literature (Bloom, 1999). However, now educators must train students themselves to assess the validity of what they encounter. What 
defines information as valid has not changed over the years, but what defines publishable information has certainly changed with increased use of the Internet. The official documents to which Lyman (2001) alludes used to be the only documents readily available. Now unofficial documents may appear official to the indiscriminate viewer. With much less than $1 \%$ of new information produced in 1999 being printed on paper (Lyman, 2001) and knowing that much of the vast amount of information published digitally is unofficial, we see that the proverbial problem now facing students is finding the official needle in the haystack. One might argue that proper search technique allows one to find the needle, yet it is increasingly clear that search technique may only limit the quest to one of many haystacks. Instead, knowledge of how information is generated, reviewed, published, and referenced in a particular field is necessary to serve as the magnet for the needle. Therefore, it must be the goal of educators to provide students with this magnet early in their undergraduate careers.

The Associated Colleges of the South (http://www. colleges.org), a consortium of 16 distinguished liberal arts institutions, defines information fluency in the following way. "Using critical thinking skills and appropriate technologies [the information-fluent individual], integrates the abilities to collect the information necessary to consider a problem or issue, to employ critical thinking skills in the evaluation and analysis of the information and its sources, and to formulate logical conclusions and present those conclusions in an appropriate and effective way" (Associated Colleges of the South, 2002).

The juxtaposition of information fluency and the scientific method has been one goal of an introductory biology laboratory course at our institution for several years. Our initial experience with fostering information fluency in the context of laboratory research underscored the need for a more refined and collaborative approach. Despite more careful guidance in assignments, incoming students seemed less and less able to evaluate information sources critically. We conjectured that while incoming students show a growing propensity to use the Internet as their primary information resource, they are perhaps even less familiar with the ways in which information is generated and reported in the field of biology. Thus, we felt it critical to collaborate with information services staff, librarians, and students to formulate the most effective approaches for fostering information fluency among our students and ourselves. Although our efforts were initially directed toward an introductory zoology laboratory, we have adapted the approach to our new introductory course focusing on molecular and cellular biology.

\section{METHODS}

\section{Pedagogical Design}

The introductory biology laboratory highlighted here occupies one semester, with multiple sections of approximately 24 students meeting one afternoon per week for $3 \mathrm{~h}$. We sought to provide students with practice and understanding of the scientific method. This included the ability to find and evaluate primary (peer-reviewed) and secondary literature and use that information in supporting hypotheses and conclusions, to conduct experiments and analyze results, to present results and conclusions orally and in writing, and to document and reference information appropriately. Instruction included a class presentation by the campus library's electronic resources librarian; a written description of the modes of reporting information in biology describing the roles of primary literature, reviews, academic texts, and popular press; and a worksheet illustrating important points of each. Students then used this instruction to guide their library research and writing on a course-related topic assigned by the professor. Throughout the semester, we provided students with assignments, exercises, and handouts to lead them through individual steps of these processes. Each assignment built on the previous ones and gave the students progressively more autonomy. Finally, the semester's activities culminated with independent laboratory research projects designed and conducted by the students. Students reported their work in oral presentations facilitated by PowerPoint. Project proposals, course syllabus, exercises, and survey with results are available online (Lindquester, 2002). The course syllabus and exercises are also available in the following Appendices.

Appendix 1: Syllabus

Appendix 2: Schedule of Assignments

Appendix 3: Literature Reference Worksheet

Appendix 4: Information Structure and Use in Biology

Appendix 5: Citation Guidelines

Appendix 6: Process Diversity Paper Instructions

Appendix 7: Development Experiment Report Guidelines

Appendix 8: Renal Function Experiment Worksheet

Appendix 9: Behavior Experiment Report Guidelines

Appendix 10: Proposal Preparation Guidelines

Appendix 11: Scientific Presentation Guidelines

Appendix 12: Ecology Experiment Worksheet

\section{Assessment Survey}

We designed the survey to evaluate the influence of the introductory biology laboratory on the perceptions and abilities of students to gain confidence regarding different technologies, information sources, and research skills. Students answered whether or not they used a particular program, skill, or resource (Table 1). If affirmative, students then rated their level of confidence in the use of that particular program, skill, or resource. Ratings ranged from 1 to 5 , with 5 being the most confident. We used the same web-based survey at the beginning and end of the course. Students knew that the course required completion of the survey, and they received credit for completing the survey. However, all responses were confidential; students were informed that instructors had no way to correlate respondents and their responses.

\section{Statistical Analyses}

We assembled the before and after responses in an Excel spreadsheet and calculated the percentage of users for each program, skill, or resource in addition to the mean confidence level for affirmative users only. We did not include confidence levels reported by negative users. End usage for each variable, percent change, and mean confidence levels before and after the course comprised our results. For before and after comparisons, the survey data 
Table 1. Survey contents: The Web-based survey asked students whether they used the following programs, performed the listed critical thinking skills, or conducted these library activities

\begin{tabular}{|c|c|c|}
\hline Programs & Critical thinking skills & Library activities \\
\hline 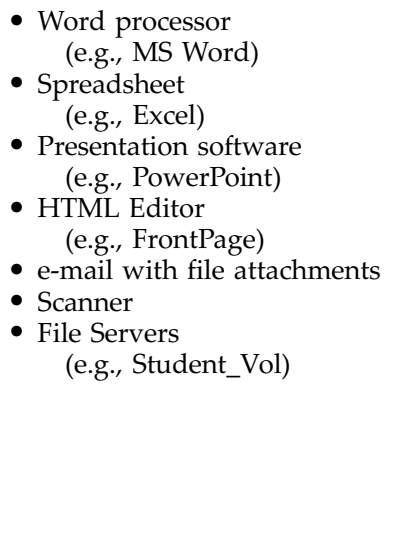 & $\begin{array}{l}\text { - Worked with others to identify research topic } \\
\text { - Gathered Web-published background information } \\
\text { - Gathered print-published background information } \\
\text { - Modified or changed a topic based } \\
\text { on background research } \\
\text { - Started background research } 4 \text { weeks } \\
\quad \text { prior to due date } \\
\text { - Started background research } 2 \text { weeks } \\
\quad \text { prior to due date } \\
\text { - Started background research } 1 \text { week } \\
\text { - prior to due date } \\
\text { - Copared a formal proposal } \\
\text { - Conducted scientific experiment of own design } \\
\text { - Prepared formal written report of experiment } \\
\text { - Prepared formal oral report of experiment } \\
\text { - Developed own, new ideas or experiments }\end{array}$ & $\begin{array}{l}\text { - Used a general Web search engine } \\
\text { - Used a scientific Web search engine } \\
\quad \text { (e.g., Medline) } \\
\text { - Used online databases (e.g., InfoTrac) } \\
\text { - Used Rhodes online catalogue } \\
\text { - Consulted with a Rhodes librarian } \\
\text { - Used hard copy periodicals in library } \\
\text { - Used hard copy scientific journals } \\
\text { in library } \\
\text { - Used hard copy books in library } \\
\text { - Used abstracts only of online } \\
\text { - Usientific journals } \\
\text { - scientific journals } \\
\text { - Asked for an interlibrary loan }\end{array}$ \\
\hline
\end{tabular}

Confidence levels can be found in Tables $2-4$.

did not fit a normal distribution in most cases and could not be transformed successfully. Therefore, we used nonparametric statistics. To evaluate the impact of the laboratory course statistically, we ran Mann-Whitney $U$ (MWU) tests on the before and after confidence levels.

\section{Comparisons between Skills or Activities}

For questions that are directly related to each other, we compared confidence levels before and after using a two-way analysis of variance (ANOVA). Although the data did not meet a normal distribution and could not be successfully transformed, we employed two-way ANOVAs for these analyses. We lacked the software necessary to do nonparametric, multiway analysis. Although nonparametric tests would be preferable, ANOVA is robust for the assumption of a normal distribution (Zar, 1996). We give the significance term of the variable, which gives information about whether the two or three variables significantly differ, regardless of time. If three variables occurred, we performed a Tukey's Multiple Comparison Test (MCT) to elucidate the specific differences between variables. The significance term of the time-by-rating interaction specifies if the confidence level significantly changed between variables over time. For example, a twoway ANOVA could evaluate whether the confidence levels of students differed in giving written versus oral reports before and after the course. We performed all statistical analyses using SPSS version 10.1 and created graphs in Excel.

\section{Graphical Analyses}

In addition to evaluating use of programs, skills and resources, the survey asked students to evaluate the qualities of four information sources (i.e., textbook, review paper, Web site, or journal article). For these questions, inferential statistics are not appropriate so we simply plotted the change in response before and after the course or the evaluation breakdown. In this case, a negative number denotes that fewer students reported that a particular source best matched the question. In addition, we did test for a change in confidence over time regarding assessing these four information sources using MWU tests.

\section{Independent Data}

In addition to student self-reporting in the survey, throughout the semester we tracked usage statistics for the three databases introduced to the students at the beginning of the term and compared database usage to the same months the previous year.

\section{RESULTS}

Nearly 100 students participated fully in both surveys (98 before and 95 after). Tables $2-4$ provide the results of statistical tests.

Table 2. Results of Mann-Whitney $U$-tests investigating whether confidence levels in program use significantly increased from the beginning to the end of the semester

\begin{tabular}{|c|c|c|c|}
\hline Program & $\begin{array}{l}\text { Responses }(N) \\
\text { before course }\end{array}$ & $\begin{array}{l}\text { Responses }(N) \\
\text { after course }\end{array}$ & $p$ value \\
\hline $\begin{array}{c}\text { - Word processor } \\
\text { (e.g., Word) }\end{array}$ & 97 & 94 & .002 \\
\hline $\begin{array}{l}\text { - Spreadsheet } \\
\text { (e.g., Excel) }\end{array}$ & 88 & 88 & $<.001$ \\
\hline $\begin{array}{c}\text { - Presentation software } \\
\text { (e.g., PowerPoint) }\end{array}$ & 98 & 94 & $<.001$ \\
\hline $\begin{array}{l}\text { - HTML Editor } \\
\text { (e.g., FrontPage) }\end{array}$ & 32 & 34 & .008 \\
\hline $\begin{array}{l}\text { - e-mail with file } \\
\text { attachments }\end{array}$ & 87 & 90 & $<.001$ \\
\hline - Scanner & 63 & 54 & .433 \\
\hline $\begin{array}{l}\text { - File Servers } \\
\quad \text { (e.g., Student_Vol) }\end{array}$ & 86 & 92 & $<.001$ \\
\hline
\end{tabular}

Significant $p$ values appear in bold. 
Table 3. Results of Mann-Whitney $U$-tests investigating whether confidence levels in skill use significantly increased from the beginning to the end of the semester

Cet change $\quad$ Responses $(N) \quad$ Responses $(N)$

Critical thinking skill in users $(\%)$ before course $p$ value

- Worked with others to identify research topic

- Gathered Web-published background information

- Gathered print-published background information

- Modified or changed a topic based on background research

- Started background research 4 weeks prior to due date

- Started background research 2 weeks prior to due date

- Started background research 1 week prior to due date

- Prepared a formal proposal

- Conducted scientific experiment of own design

- Conducted statistical analysis

- Prepared formal written report of experiment

- Prepared formal oral report of experiment

- Developed new ideas or experiments based on background information

$\begin{array}{cccc}+10.2 & 88 & 94 & .036 \\ +3.1 & 95 & 94 & .051 \\ +3.0 & 93 & 93 & .774 \\ -3.0 & 83 & 76 & .119 \\ -22.4 & 63 & 42 & .185 \\ -1.3 & 85 & 82 & .009 \\ +5.9 & 85 & 88 & .233 \\ +42 & 46 & 86 & .161 \\ +48.8 & 45 & 89 & .001 \\ +30.6 & 66 & 94 & .030 \\ +24.8 & 64 & 93 & .003 \\ +51.7 & 36 & 82 & .001 \\ +41.3 & 39 & 77 & .003\end{array}$

Significant $p$ values appear in bold.

\section{Programs}

Nearly $100 \%$ of participants reported that they used word processing (Word), spreadsheet (Excel), and presentation (PowerPoint) programs by the end of the course. Fewer students used HTML programs (FrontPage) and a scanner. The use of these programs also did not increase dramatically with the course. We found generally high confidence in use of programs, and confidence significantly increased with time, except in the use of scanners (Figure 1; Table 2). Confidence in spreadsheet, presentation, and HTML programs ranked lower than with word processing, e-mail, or use of the file server (i.e., an on-campus network). Note that this course did not incorporate use or instruction in HTML or scanning, although students did have access to a scanner and some may have used it when preparing PowerPoint presentations.

\section{Skills}

We witnessed relatively large increases (20\%-60\%) in the numbers of students preparing proposals, conducting inde- pendent research, conducting statistics, and presenting their work (Table 3). Student confidence levels also generally rose with each skill (Figure 2), some statistically significant (Table 3). Significantly more students reported consulting with people about topics after taking the course (MWU, $p=.036$ ). Nearly all students reported gathering both print and Webbased information both before and after the course (MWU, $p>$.05). After taking the course, $22.4 \%$ fewer students stated that they begin a project 4 weeks early (Table 3). Confidence levels did not increase in proposal writing (MWU, $p=.161$ ), which may be understandable given the rigorous critique of proposals by professors during the course. However, we did find significant increases in students' confidence levels regarding performing experiments, conducting statistics, giving written and oral presentations, and coming up with original ideas (Figure 2; Table 3).

\section{Library Resources}

We found the greatest increase in the number of students reporting their use of a scientific search engine (64.2\% Table 3).

Table 4. Results of Mann-Whitney $U$-tests investigating whether confidence levels in library activities significantly increased from the beginning to the end of the semester

\begin{tabular}{|c|c|c|c|c|}
\hline Library activity & Net change in users $(\%)$ & Responses $(N)$ before & Responses $(N)$ after & $p$ value \\
\hline - Used a general search engine & -1.1 & 98 & 93 & .115 \\
\hline - Used a scientific search engine & +64.2 & 33 & 92 & .254 \\
\hline - Used an online database & -3.0 & 63 & 66 & .225 \\
\hline - Used campus online catalogue & +19.3 & 75 & 90 & .041 \\
\hline - Used online catalogues of other local libraries & +17.3 & 46 & 60 & .507 \\
\hline - Consulted with a librarian & +16.3 & 49 & 61 & .062 \\
\hline - Used hard copy general periodicals in the library & -2.3 & 59 & 55 & .066 \\
\hline - Used hard copy scientific journals in the library & +23.4 & 39 & 60 & .846 \\
\hline - Used hard books in the library & +16.4 & 77 & 91 & .343 \\
\hline - Used only abstracts in online scientific journals & +47.8 & 48 & 92 & .469 \\
\hline - Used full text articles in online scientific journals & +44.6 & 46 & 87 & .731 \\
\hline - Asked for an interlibrary loan & $-1.6 \%$ & 16 & 13 & .268 \\
\hline
\end{tabular}

Significant $p$ values appear in bold. Near significant $p$ values are italicized. 


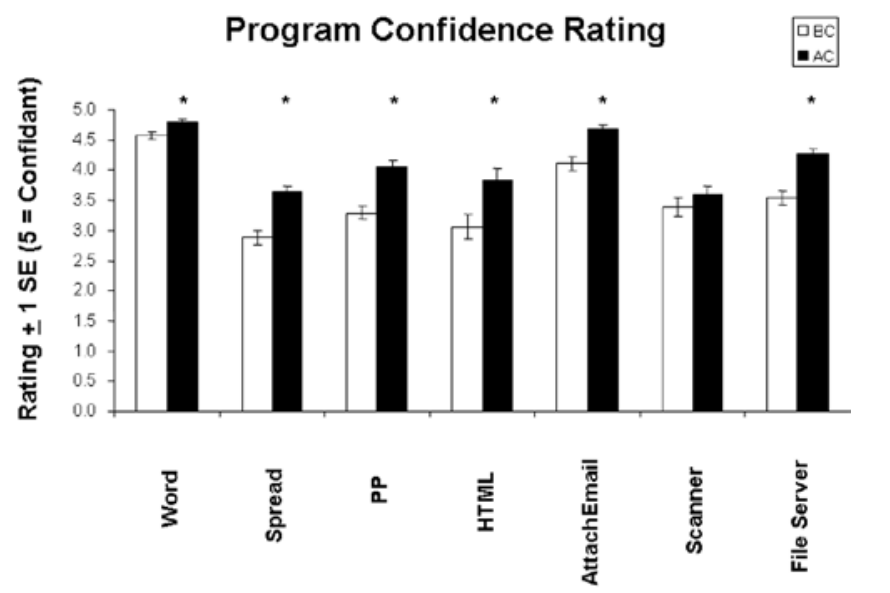

Types of Program

Figure 1. How students perceive their confidence in using different programs. Errors represent standard error. Confidence in program use ( ${ }^{*}$ denotes $p<.05$ from Mann-Whitney $U$-tests) significantly increased for all programs except the ability to scan.

Less than $80 \%$ of our students used online databases or the online catalogue of an off-campus, local university library. In addition, only $49 \%$ of students requested help from a campus reference librarian (Table 4). A significant increase (19.3\%) in the number of students using the campus online catalogue led to nearly $100 \%$ end usage (MWU, $p=.041$ ). Trends indicate that more students reported consulting hard copies of books and journals, in addition to online journals, after taking the course (Table 4), although changes in confidence levels of these activities did not meet the criteria for statistical significance (Figure 3). Only $16.3 \%$ of our students used interlibrary loan, and participation in the course did not dramatically increase use of this resource (only 3.5\%), possibly due to the relatively short time frame of each

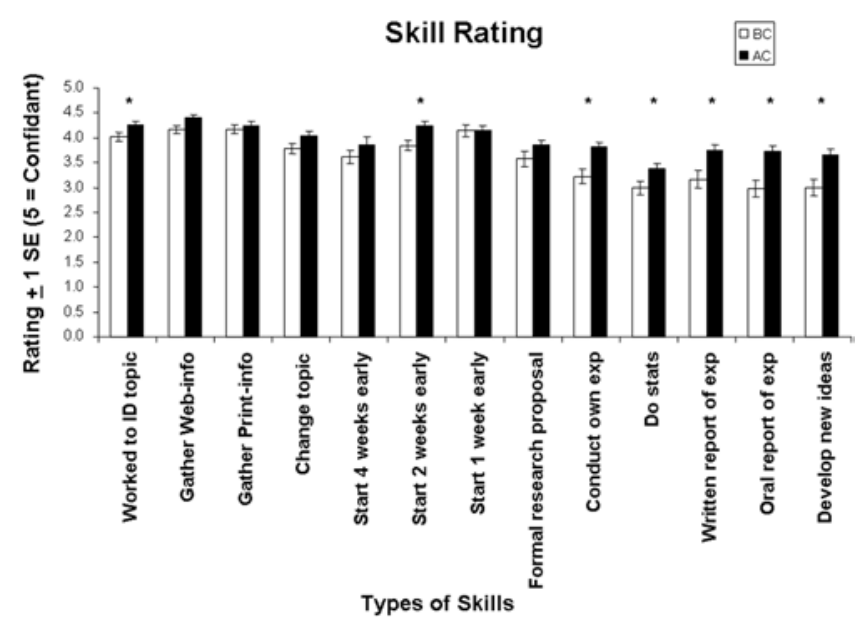

Figure 2. How students perceive their confidence in performing different skills. Errors represent standard error. An * denotes a significant increase in confidence in skill performance $(p<.05$ from Mann-Whitney U-tests).

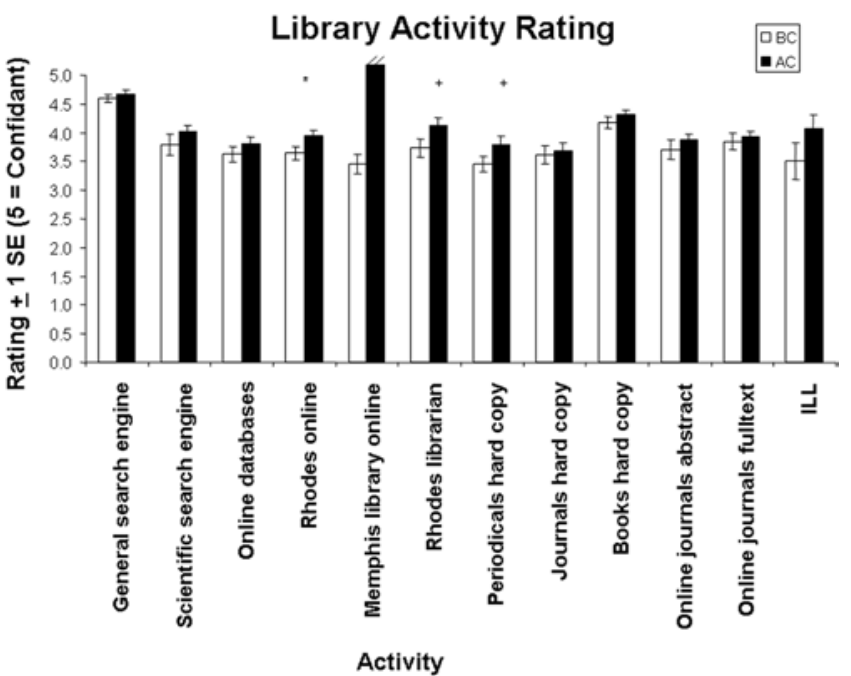

Figure 3. How students perceive their confidence in performing different library activities. Errors represent standard error. An * denotes a significant increase in confidence in skill performance $(p<$ .05 from Mann-Whitney $U$-tests). A + denotes confidence values that neared significance (i.e., a $p$ value $>.05$ but $<$ than .10 ).

assignment. Confidence ratings for most library skills did not significantly differ with time (Figure 3), although two approached significance (MWU, $p=.062$ and .066 for asking a reference librarian and using hard copies of periodicals, respectively; Table 4).

As an assessment of usage of library resources independent of student self-reporting, we tracked database usage during the semester of the course and compared usage levels with the same months the previous year when no specific library instruction had been given to introductory biology students. Table 5 indicates a large increase in usage of the databases that were recommended for student use for this course. The large increases occurred in the first month when

Table 5. Scientific database usage

\begin{tabular}{clrcr} 
Database & Month & Usage 2001 & Usage 2002 & \% Increase \\
\hline Cambridge & September & 134 & 1181 & 781 \\
Scientific & October & 514 & 1742 & 239 \\
Abstracts & November & 1081 & 2066 & 91 \\
& December & 628 & 1320 & 110 \\
BioOne & September & 0 & 135 & \\
& October & 15 & 145 & 867 \\
& November & 7 & 105 & 1400 \\
Medline & December & 19 & 146 & 668 \\
& September & 117 & 192 & 64 \\
& October & 83 & 160 & 93 \\
& November & 115 & 247 & 115 \\
& December & 19 & 115 & 505 \\
\hline
\end{tabular}

Note. Usage of databases introduced to the students at the beginning of the semester is indicated for each month of the fall semester in 2002 (when the study was conducted) and compared with usage in the same months of 2001 (when no database instruction was given to students). 


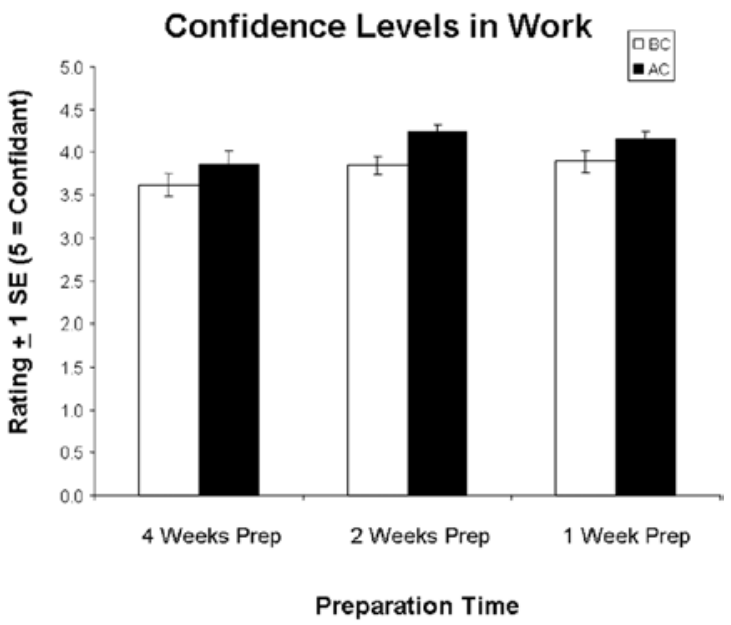

Figure 4. Students' confidence levels in work started 4, 2, or 1 week before the deadline. Open bars represent ratings before the course and shaded bars indicate responses following the course. Errors are $1 \mathrm{SE}$.

a worksheet specifically required database usage. Furthermore, high usage levels persisted throughout the semester, suggesting that students continued to use the databases for research in later assignments.

\section{Comparison of Skills or Activities}

Confidence in work increased with the amount of preparation time (Figure 4; two-way ANOVA, prep time, $F_{2,439}=3.533, p=.03$ ) and from the beginning to the end of the semester (time, $F_{1,439}=9.427, p=.002$ ). However, we did not find a significant interaction (prep time by time, $\left.F_{2,439}=.30, p=.741\right)$. Similarly, students showed a higher confidence level in using general versus scientific search engines (Figure 5; two-way ANOVA, search engine, $\left.F_{1,312}=65.565, p=.001\right)$ and confidence in use of both search engines increased over time (time, $F_{1,312}=3.987, p=.047$ ),

\section{Confidence Levels in Web Searching}

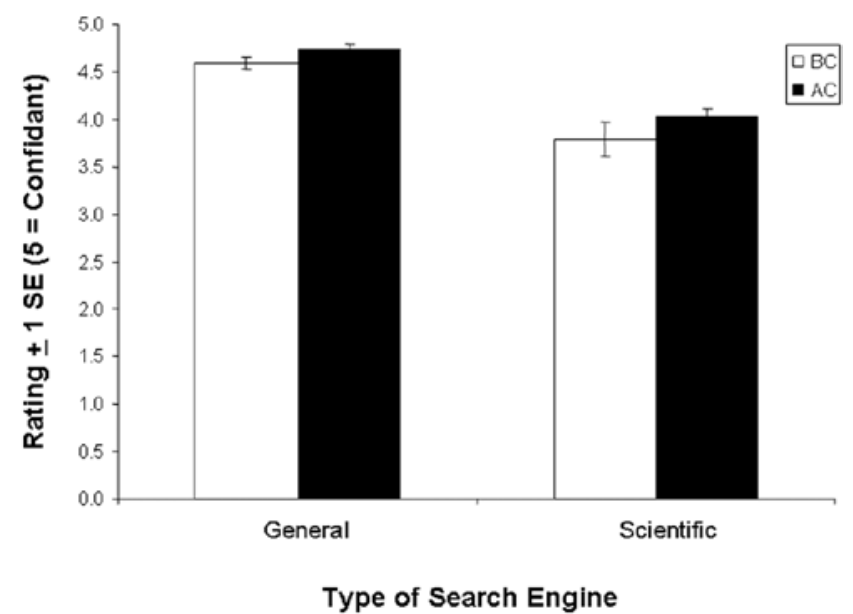

Figure 5. Confidence levels reported by students regarding using Web search engines. Open bars represent ratings before the course and shaded bars indicate responses following the course. Errors are $1 \mathrm{SE}$. resulting in a nonsignificant interaction (search engine by time, $F_{1,312}=.256, p=.613$ ). Although not provided as a graph, we also found a statistical difference in confidence levels between using the campus library's online catalogue versus a catalogue from an off-campus, local university library (two-way ANOVA, library, $F_{1,267}=4.446, p=.036$; time, $\left.F_{1,267}=4.229, p=.041\right)$. However, confidence levels in the use of information from print sources versus Web sources did not differ (two-way ANOVA, source, $F_{1,371}=.745$, $p=.389$; time, $\left.F_{1371}=3.307, p=.70\right)$. Statistics from either of these skills (library or print source) did not result in significant interactions.

In terms of print sources, students showed the highest confidence in their use of hard copy books compared with journals and periodicals (Figure 6; two-way ANOVA, source, $\left.F_{2,375}=17.174, p<.001\right)$, and this did not differ significantly with time (time, $F_{1,375}=2.854, p=.092$ ) or with a time by source interaction (time by source, $F_{2,375}=.588, p=.556$ ). Confidence use did not differ significantly between hard copy journals and periodicals (Tukey's MCT, $p=.967$ ). Student confidence in giving reports significantly increased (two-way ANOVA, time, $F_{1}, 225=23.401, p<.001$ ), regardless of report type $\left(F_{1,225}=.653, p=.420\right)$. Because of statistical constraints, we could not test confidence levels between using hard-bound versus online journals or reading abstracts versus full-text of journals online.

\section{Source Evaluation}

After taking the biology course, $19.5 \%$ more students thought journal articles provided the most detailed information (74.7\%; Figure 7a) and rated their opinion with significantly higher confidence (Figure 7b; MWU, $p<.001$ ). Textbooks lost recognition $(-22.8 \%)$ as source of the most detailed information (Figure 7a) but gained as the source of the best overview (18.5\%), although not significantly (Figure $7 \mathrm{c}$; $p=.362)$. By the end of the course, students generally thought that review papers (43.3\%) and journals (51.6\%) equally published the results of research reviewed by scholars in the field (Figure 8a) and confidence in this opinion also increased

\section{Confidence Levels in Using Hard Copy Sources}

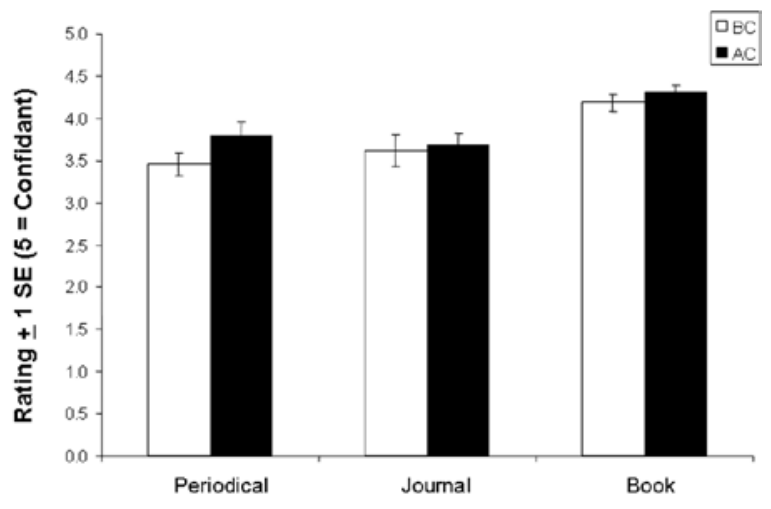

Type of Hard Copy Source

Figure 6. Students' confidence in using different hard copy sources. Open bars represent ratings before the course and shaded bars indicate responses following the course. Errors are $1 \mathrm{SE}$. 


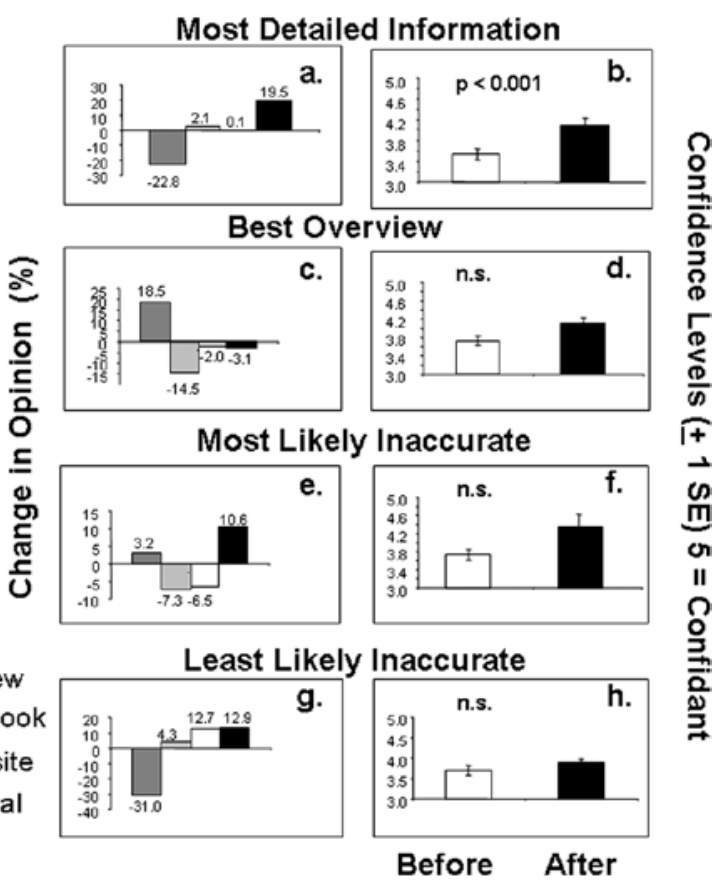

Figure 7. Change in student opinion (panels a, c, e, g) and confidence levels $(b, d, f, h)$ regarding the accuracy and information content of four sources (review article, textbook, Web site, or journal article). See Table 1 for complete descriptions of questions. Panels a, $c$, e, and $g$ report change in opinion as a percentage. Significant results are reported with $p$ values from Mann-Whitney $U$-tests of confidence levels before and after the course. Error $=\mathrm{SE}$.

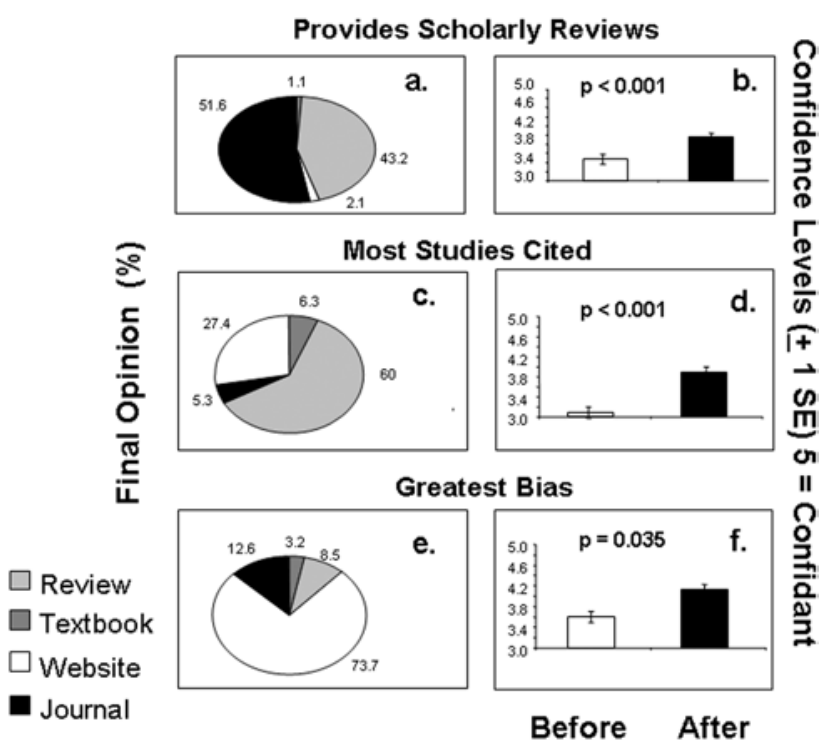

Figure 8. Student opinion (panels a, c, e) and change in confidence levels $(b, d, f)$ regarding the accuracy and information content of four sources (review article, textbook, Web site, or journal article). See Table 1 for complete descriptions of questions. Panels a, c, and e show pie graphs to indicate which sources students reported best fit the category during the survey conducted at the end of the course. Significant results are reported with $p$ values from Mann-Whitney $U$ tests of confidence levels before and after the course. Error $=\mathrm{SE}$. significantly (Figure 8b; MWU, $p<.001$ ). Before the course, mixed responses occurred regarding the source that could cite the largest number of scientific studies reporting common themes. By the end (Figure 8c), students increased their confidence (Figure 8d; MWU, $p<.001$ ) in identifying review articles $(60 \%)$ as the best source for citation, followed by journal articles $(27.4 \%)$.

Students also possessed mixed opinions regarding which source provided the most bias. However, by the end of the course, most students (Figure 8e; $73.7 \%$, a $21.6 \%$ increase) agreed with higher confidence (Figure 8f; MWU, $p=.035$ ) that Web sites are most likely to have the greatest bias. Most students also suggested Web sites as the most likely source of inaccurate information $(81 \%$ and $74 \%$, before and after, respectively). Interestingly, in the second survey, more students $(10.6 \%)$ thought journal articles could provide inaccurate information (Figure 7e), although this did not prove to be a significant increase (Figure 7f). In contrast, students increased their opinion that journal articles would be the least likely to be inaccurate (12.9\%). With this increase, the likelihood that textbooks served as the sources least likely to be inaccurate declined (31\%; Figure $7 \mathrm{~g}$ ). Confidence levels for the assessment of most and least likely inaccurate did not differ significantly (Fig. 7f and h).

\section{DISCUSSION}

The similarities in the steps of the scientific method and the Associated Colleges of the South's definition of information fluency are readily apparent (Associated Colleges of the South, 2002). In fact, to train students fully in the scientific method, we must necessarily train them to be information fluent. By addressing both goals in a concerted fashion, we ensure that our students know how to use the most current tools to access information, evaluate the information in ways appropriate to the discipline and the problem they wish to address, use the information to inform their scientific study, carry out and analyze their study, and ultimately add to the body of information with new results presented in a relevant forum. Thus, information fluency is requisite to proficiency with the scientific method.

The exercises developed for this course introduced students in a progressive, increasingly complex manner to the principles and practices of information fluency. They began with basic introduction to library resources and led to use of such skills and resources in the development, implementation, and presentation of an independent research project. Our survey results indicate that following the course, increases occurred, some statistically significant, in the number of students using various library-related resources, in the numbers and confidence levels of students using various technologies, and in the numbers and confidence levels of students involved in various activities related to the scientific method. We must caution that the survey method of assessment used here is limited in that it only represents student opinion of progress in the course. Anecdotal evidence of student performance reported by the teaching faculty supports the survey results; however, we did not perform an independent, systematic analysis of student improvement in this study. Nevertheless, we anticipate that with the foundation gained in this introductory course, students will build on their skill and confidence in upper-level biology courses as well as other disciplines. 
Although these exercises were developed initially for an introductory course in zoology, the lessons learned can be applied to any introductory level biology course. The essential elements are that students are instructed in both the scientific method and in the proper use of library resources to support scientific research. The instruction should include series of exercises ranging progressively from simple worksheet and essay assignments that require library research and citation to independent laboratory projects leading to oral, poster, written presentation, or a combination of these. In fact, our current introductory cell biology laboratory includes three such projects, each with a different presentation format (Biology I, 2003).

\section{CONCLUSION}

In general, students reported an increase from the beginning to the end of the semester in information fluency as measured by confidence in computer technology, critical thinking skills, and library activities. However, this study still points to the need to train our students to evaluate scientific resources critically. As more and more information pours on to the Internet daily, it becomes harder and harder to distinguish "good" science from "bad." Until guidelines are established for peer review of scientific content of Web sites, educators must design laboratory exercises that train and test students' ability to process information.

Despite increases in the students' confidence with regard to information fluency, we could still identify several areas in which students still need to increase their level of confidence: execution and analysis of experiments, use of online resources, and familiarity with interlibrary loan. Library skills overall seemed to show lower confidence ratings. In addition, student opinion varied as to the accuracy, potential bias, and content of different information sources. These results further emphasize the need for academic departments to work with library staff in hopes of increasing the information fluency of students. Collectively, our efforts as educators can have profound impact on our students' ability to navigate the world of scientific information now available to us on the Internet.

\section{ACKNOWLEDGMENTS}

The authors appreciate the advice and participation of the other professors in the introductory biology laboratory (Tony Becker, Jay Blundon, Alan Jaslow, David Kesler), and of Allison Gratzer (Rhodes Class of 2002), Darlene Brooks (Electronic Resources Librarian), and Robert Johnson (Dean of Information Services). A grant from the Andrew W. Mellon Foundation to the Associated Colleges of the South provided support for this work.

\section{REFERENCES}

Associated Colleges of the South. (2002). ACS IF definition. http:// www.colleges.org/ if/if_definition.html (accessed 22 January 2003).

Bloom, F.E. (1999). The importance of reviewers. Science 283, 789.

Biology I. (2003). Biology 131 laboratory syllabus. http://www. rhodes.edu/biology/biologyi/10130labsyl.html (accessed 2 July 2004).

Biological Science Curriculum Study. (1993). Developing Biological Literacy: A Guide to Developing Secondary and Post Secondary Biology Curriculum, Dubuque, IA: Kendall/Hunt.

Lindquester, G. (2002). Rhodes Biology Information Fluency Project. http://www.rhodes.edu/biology/glindquester/infoflu/index.html (accessed 2 July 2004)

Lyman, P. (2001). Information literacy. Liberal Educ., 87, 28-37.

National Research Council. (2002). BIO2010: Transforming Undergraduate Education for Future Research Biologists, Washington, DC: National Academies Press.

Siebert, E.D., and McIntosh, W.J. (2001). College Pathways to the Science Education Standards, Arlington, VA: National Science Teachers Association.

Zar, J.H. (1996). Biostatistical analysis, 3rd ed., New Jersey: Prentice Hall. 


\section{Appendix 1: Syllabus \\ Zoology Laboratory - Biology 121 \\ 2002 Syllabus}

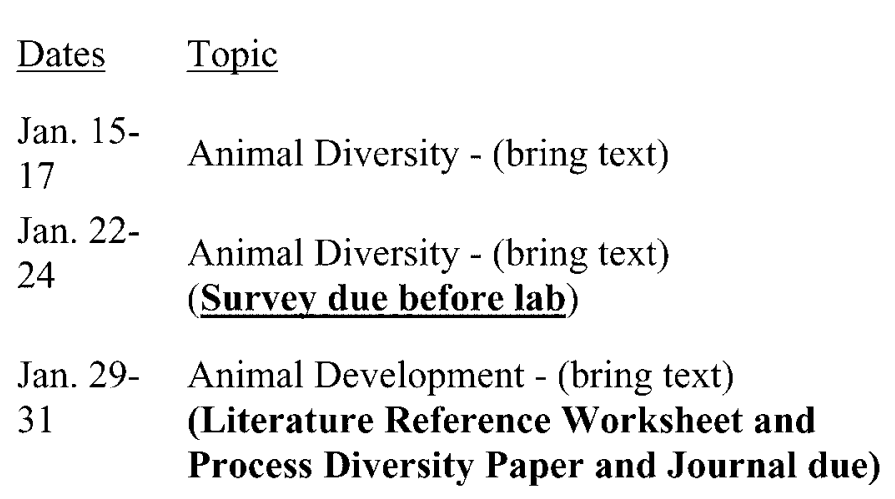

Feb. 5-7 Digestive and Respiratory Systems

Feb. 12- Circulatory System

14 (Development Report due)

Feb. 19-

21

Feb. 26-

28

Urogenital and Nervous Systems

Renal Function Experiment

Mar. 5-7 Spring Break

Mar. 12- Physiology Equipment Demonstrations

14 (Renal Function Worksheet due)

Mar. 19- Behavior

21 (Behavior Reports due at end of day)

Mar. 26- Discussion of Group Projects

28 (Group Research Proposal due)

(Note: The $28^{\text {th }}$ is Easter break but Thursday lab groups will schedule an appointment with their professor to meet earlier in the week.)

Apr. 2-4 Work on group projects

Apr. 9-11 Work on group projects

Apr. 16- Presentations [or Ecology (depending on weather)]

18 (Group Research Presentation due)

Apr. 23- Ecology [or Research Presentations (depending on 25 weather)]

(Survey due before lab, Ecology Worksheet due TBA)

\author{
Quiz
WebCT
(due by
4:00)

reading $\underline{\mathrm{LM}}^{1}\left(\underline{\mathrm{DG}}^{2}\right)$

1

Quiz 12
Quiz $23(\mathrm{pp} \mathrm{1-3,} \mathrm{Ch}$ $1,4,6)$
Quiz 34 (Ch 5)

Quiz $4 \quad 5($ Ch 7,8)

Quiz $5 \quad 6$

7

Quiz $6 \quad 8$

\section{Goals}


After successfully completing this laboratory course, the student should be able to

1. characterize the diversity of animals on earth and the means by which they are classified

2. describe the basic processes and stages of vertebrate development

3. understand how animals exist and function with a variety of specialized tissues and organ systems

4. apply the scientific method to the study of animal physiology, behavior and ecology, and

5. appropriately use references and statistical analysis.

\section{Grading}

\begin{tabular}{|l||l|}
\hline WebCT Quizzes and Survey & 5 \\
\hline Literature Reference Worksheet & 10 \\
\hline Process Diversity Paper \& Journal & 15 \\
\hline Quizzes, 6 total & 60 \\
\hline Development Experiment & 15 \\
\hline Renal Function Experiment & 10 \\
\hline Behavior Experiment & 10 \\
\hline Group Research Project & 50 \\
\hline Ecology Experiment & 10 \\
\hline Total & 185 \\
\hline
\end{tabular}

Grades will be assigned according to the following scheme:

$$
\begin{aligned}
& 100-90 \%=\mathrm{A} \text { to } \mathrm{A}- \\
& 90-80 \%=\mathrm{B}+\text { to } \mathrm{B}- \\
& 80-70 \%=\mathrm{C}+\text { to } \mathrm{C} \text {, etc. }
\end{aligned}
$$

where $80-82 \%=\mathrm{B}-, 83-86 \%=\mathrm{B}, 87-89 \%=\mathrm{B}+$, etc.

All assignments are due on the dates given on the syllabus. Others assignments and due dates may be given in class. Late assignments will be accepted 
(resulting in mandatory point deductions) only at the discretion of the professor.

\section{Attendance}

Attendance is required. Missed work cannot be made up; a grade of zero will be recorded for missed work. If there are extenuating circumstances, students may be able to attend a different laboratory section only with advance permission from both the regular professor and the professor whose section the student wishes to attend. 


\section{Appendix 2: Schedule of Assignments}

\section{Zoology Laboratory - Biology 121 \\ 2002 Assignments}

The goals of this laboratory course are to enable students to:

1. characterize the diversity of animals on earth and the means by which they are classified

2. describe the basic processes and stages of vertebrate development

3. understand how animals exist and function with a variety of specialized tissues and organ systems

4. apply the scientific method to the study of animal physiology, behavior and ecology, and

5. appropriately use references and statistical analysis.

Practical laboratory exercises and quizzes accompanied by the following assignments further these goals. Click on the name of each assignment to access the assignment details and information.

Assignment
$\begin{aligned} & \text { Entry Survey } \\ & \text { WebCT Quizzes }\end{aligned}$
Section 1 - C. Jaslow - Tue
Section 2 - T. Becker - Tue
Section 3 - G. Lindquester - Wed
$\quad$ Section 4 - T. Becker - Thu
$\quad$ Section 5 - G. Lindquester - Thu
Literature Reference Worksheet
Process Diversity Paper and Journal
Development Experiment Report
Renal Function ExperimentWorksheet
Behavior Experiment Report
Group Research Proposal
Group Research Presentation
Exit Survey
Ecology Experiment Worksheet

\section{Date assigned Date due}

Jan 15-17 Jan 22-24 - before lab

Jan 15-17 Jan 22-24 - end of lab (4:00)

Jan 22-24 Jan 29-31

Jan 22-24 Jan 29-31

Jan 29-31

Feb 12-14

Feb 26-28 Mar 12-14

Mar 19-21

Mar 12-21

Mar 19-21 - end of lab

Mar 26-28

Mar 26-28

Apr 16-18

Apr 16-18

Apr 23-25
Apr 23-25 - before lab

TBA by Professor 


\section{Appendix 3: Literature Reference Worksheet}

\section{Literature Reference Worksheeet}

Step 1 - Print a copy of this worksheet.

Step 2 - Refer to the document Information Structure and Use in Biology. As you read that document, refer back to this Worksheet and complete the checklist and exercises when prompted to do so.

Step 3 - Turn in this worksheet to your lab professor by the due date and time stated in the course syllabus. Be sure to write your name and lab section on the top.

\section{Items:}

1. In which of the two papers, Example 1 or Example 2 (check one), is it easiest to find the various sections (Abstract, Introduction, Methods, Results, Discussion).

2. Given these four resources:

1. A scientific textbook

2. A scientific review article

3. A scientific article in a website, newspaper, or magazine

4. A scientific journal article

Please answer the following questions with the most appropriate number.

\begin{tabular}{|l|c|c|c|c|}
\hline \multirow{2}{*}{} & \multicolumn{4}{|c|}{ Resource Number } \\
\cline { 2 - 5 } & 1 & 2 & 3 & 4 \\
\hline A. Has the most detailed, primary information on a topic? & 0 & 0 & $\bigcirc$ & $\bigcirc$ \\
\hline B. Is LEAST likely to provide reliable or accurate information? & $\bigcirc$ & 0 & $\bigcirc$ & $\bigcirc$ \\
\hline C. Gives the best general, broad overview of a topic? & $\bigcirc$ & $\bigcirc$ & $\bigcirc$ & $\bigcirc$ \\
\hline $\begin{array}{l}\text { D. Would cite the largest number of scientific studies, } \\
\text { reporting common themes? }\end{array}$ & $\bigcirc$ & $\bigcirc$ & $\bigcirc$ & $\bigcirc$ \\
\hline E. Is MOST likely to provide reliable or accurate information? & $\bigcirc$ & $\bigcirc$ & $\bigcirc$ & $\bigcirc$ \\
\hline $\begin{array}{l}\text { F. Publishes the results of research reviewed by scholars in the } \\
\text { field? }\end{array}$ & 0 & $\bigcirc$ & $\bigcirc$ & $\bigcirc$ \\
\hline G. Is likely to have the greatest bias? & $\bigcirc$ & $\bigcirc$ & $\bigcirc$ & $\bigcirc$ \\
\hline
\end{tabular}


3. ___ As you research your topic for the Process Diversity Paper, search each of the three citation indexes mentioned in Information Structure and Use in Biology using appropriate key words. Place a check in the blank at the left after you have done so.

4. As you research your topic for the Process Diversity Paper, search a general search engine (e.g. google.com) using appropriate key words. Select two web sites from that search that provide information you feel may be of use. Consider the evaluation criteria in the table in Information Structure and Use in Biology. Complete the following table. Write in the web site address. Then, for the five criteria below, rank each web site with a 1,2,3,4, or 5 with 5 being the best you could hope for in the ideal web site.

\begin{tabular}{|l|l|l|}
\hline & Address 1 & Address 2 \\
\hline $\begin{array}{l}\text { URL (web site } \\
\text { address) }\end{array}$ & & \\
\hline ACCURACY & & \\
\hline AUTHORITY & & \\
\hline OBJECTIVITY & & \\
\hline CURRENCY & & \\
\hline COVERAGE & & \\
\hline
\end{tabular}

5. How could you change the last sentence in the example paragraph so that the reader knows that both ideas came from Smith (2001)?

How could you change the sentence so the reader knows that the first idea about caloric demands came from Smith, but the second idea about feeding was yours?

6. On an attached page in typed text, write a paragraph summarizing the following fictional publication. Use information from this exercise and your lab manual to reference the paragraph. Include a literature cited section. 


\title{
Lake Pollution on Waterfowl in Tennessee
}

\author{
R. T. Smith and J. D. Labin \\ Journal of Tennessee Lakes, Volume 5, Pages12-18, January 2002.
}

The lakes in western Tennessee are stopovers for numerous migrating birds, including many waterfowl such as volunteer geese (Anser tennesseus) and tiger ducks (Mergus memphius) (Richards, 1985). Over the past 10 years, power plant and motorboat overflow has caused a $30 \%$ increase in lake petrochemical levels, as shown in Table I.

Table I. Levels of oil, gasoline and grease measured in Reelhand Lake by depth sampling. Values shown are mean parts per million $(\mathrm{ppm}) \pm$ standard error for 10 samples. The $*$ indicates that $\mathrm{P}<0.05$, showing that the difference between years is statistically significant using a t-test.

$\begin{array}{ccc}\underline{\text { Petrochemical }} & \underline{1990} & \underline{2001} \\ \text { oil* } & 6.2 \pm 0.7 & 9 \pm 0.4 \\ \text { gasoline* } & 15 \pm 3.4 & 19.5 \pm 4.7 \\ \text { grease } & 2.8 \pm 2.5 & 3.5 \pm 3.3 \\ \text { total petrochemicals* } & 24 \pm 1.1 & 32 \pm 1.8\end{array}$

Because of these significant increases in lake petrochemicals, we collected more ducks and geese this year with oil in their feathers (45/78 birds) than in our last sampling done in $1993(12 / 65)$. The oil was thick, black, and sludgy, and on a few of the contaminated birds $(11 \%)$, it glued together feathers so completely that patches of skin could be seen. On 4 birds, the viscous oil formed tacky globs on the beaks, where it appeared to interfere with opening and closing.

\section{Literature Cited}

Richards, D. S. 1985. Wildlife surveys of Tennessee lakes. J. of Southeastern Biology. 23:75-82.

7. Look at the references in the Information Structure and Use in Biology document for the three examples referred to in Item \#1 on this worksheet. One of these references is not cited in the form specified in the Appendix of the Zoology Laboratory Manual. 
Which reference is in the incorrect format? Example 1, Example 2, or Example 3 (check one)

8. In the space below each of the following sources, format the reference information as specified in the Appendix of the Zoology Laboratory Manual as you would include it in the Literature Cited section of a paper.

The textbook (Starr/Taggart) from your Zoology lecture class.

A publication of one of the faculty members of Rhodes' Department of Biology. (See copies of the most recent faculty publications in the cabinet next to the copy machine in the hall outside the Zoology lab.)

Copyright (C2002, Gary J. Lindquester and Carolyn R. Jaslow. All rights reserved. 


\section{Appendix 4: Information Structure and Use Information Structure and Use in Biology}

Most academic fields of study can be considered information rich. But few fields have seen the explosive expansion of new information in the past century that Biology has. Furthermore, technology is providing new ways of finding, accessing, evaluating, analyzing, and presenting information. As a biology student, it is crucial for you to understand the structural hierarchy of information in Biology and to develop the skills in using current information and ultimately in adding to the database of knowledge.

The text and exercises on and linked to this page will help you in learning about the sturcture and use of information in Biology. You should use what you learn here in all further exercises in this course and throughout your academic career in Biology unless specific instructors indicate otherwise.

If you have not already done so, print a copy of the Literature Reference Worksheet and follow its insrtuctions as you read this document.

\section{Heirarchy of Information}

\section{Generating New Information: The Scientific Method}

Most new information about the mechanisms of life come from the results and conclusions gained from experimentation. For conclusions to be valid, experiments must generally conform to the scientific method. The scientific method is discussed more fully in the textbook and will be practiced in lab.

Laboratory Notebooks - As scientists conduct experiments, they keep detailed records of their work in laboratory notebooks. To ensure scientific integrity and accountability, scientists maintain contemporary records of their work written in ink in bound, paginated books.

\section{Presenting New Information: The Scientific Meeting}

Many scientists belong to national or international organizations in their fields that hold annual meetings. Such meetings provide a forum for scientists to present the work they have recently completed. Presentations are usually given orally or in the form of a poster (look around the halls of the Biology Department for examples of posters). Feedback from other scientists at the meeting inform the presenter of other conclusions that may be drawn from the results or further work that should be done. Work presented at such meetings is often a few months to a year old.

\section{Presenting New Information: Peer Review and Primary Literature}

Once the scientist has tested a hypothesis or series of related hypotheses in a number of ways and formulated appropriate conclusions, she or he may submit a paper on the work to a peer-reviewed journal. (Note that the singular "scientist" is used here, but it is common in biology for papers to have multiple authors.) An editor of a journal sends copies of a submitted paper to several other scientists working in the particular area of 
study. These scientists become the peer-reviewers and provide comments on the validity of the experiments and conclusions and the significance of the work to the field. The reviewers provide recommendations to the editor and the editor returns the anonymous comments to the author and either accepts the paper for publication, returns the paper to the scientist for revision or further experimentation, or rejects the paper. If the paper is accepted, it is published in a future volume of the journal. It usually takes several months to a year for work to be published after it is submitted.

The format for published papers generally includes an abstract, introduction, methods, results, and discussion. Most journals publish an Instructions to Authors document that describes the details of the content and reference format. In some publication formats the sections are not so easily delineated, but if you look closely, you should find the following information.

Abstract/Summary - The abstract is a mini paper in itself. In it, you should find the introduction, methods, results and discussion summarized.

Introduction - The introduction places the current study in the context of what we already know and/or don't know about the topic at hand. It should state the hypothesis being tested and usually ends with a summary statement of the results.

Methods - Materials and methods should contain enough information, either directly or through reference to previously published work, to allow the reader to critically evaluate or even repeat the experiments.

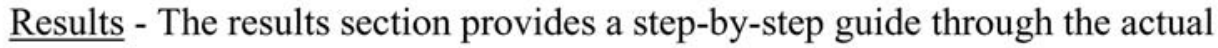
experiments and results (in the form of pictures, figures, tables - raw data or in summary or statistically reduced form). This section generally avoids interpretation of the data as it regards the hypothesis or context of the work.

Discussion - The discussion brings together the results from individual experiments in an attempt to support or refute the hypothesis. It often begins with a short summary of the results. It should point out and try to explain any conflicting results (assuming the authors chose to report those results). It should explain what impact the new information has on the existing body of knowledge. It may conclude with new questions raised by the results, provide new hypotheses to be tested and/or suggest further work to help clarify ambiguous results.

References/Literature Cited - The reference section follows the format of the publisher but ideally includes a complete reference for each cited article.

Look at the following two primary research papers available online and see if you can find the sections described above.

Example 1: Palomares P., P. Ferreras, A. Travaini, \& M. Delibes. 1998. $\underline{\text { Co- }}$ Existence between Iberian Lynx and Egyptian Mongooses: Estimating Interaction 
Strength by Structural Equation Modelling and Testing by an Observational Study. J. Animal Ecol., 67: 967-978.

Example 2: Stenseth N. C., W. Falck, K. S. Chan, O. N. Bjornstad, M. O'Donoghue, H. Tong, R. Boonstra, S. Boutin, C. J. Krebs, \& N. G. Yoccoz. 1998 From patterns to processes: phase and density dependencies in the Canadian lynx cycle. Proc. Natl. Acad. Sci. U S A 95:15430-15435.

\section{Compiling New Information: Review Articles}

Once a number of primary articles have been published by scientists on a related topic and common themes and mechanisms begin to emerge, a notable scientist in the field may write a review article. Review articles are published in many of the same journals as primary literature, and some journals are devoted solely to reviews. Reviews often cite dozens if not hundreds of references. The author tries to summarize all the work done to date (or since the last substantive review) on the topic, describe common elements, sort out discrepancies in the published information, and identify deficiencies in the available knowledge. The most recent primary literature cited in a review article is usually six months to a year old by the time the review is completed and published. See the following example review article.

Example 3: Moore JP, Parren PW, Burton DR.. 2001. Genetic subtypes, humoral immunity, and human immunodeficiency virus type 1 vaccine development. $J$. Virol. 75:5721-5729.

\section{Compiling New Information: Scholarly Books}

Books are often published for professional academic audiences. Some such books publish primary literature, often as more complete versions of work that was presented at a scientific meeting. Other books publish review articles on related topics. The editorial panel for such books is usually composed of scientists in the field who serve as critical reviewers of the scientific validity of the work.

\section{Presenting Science to a Broader Audience: Textbooks}

As a student in biology, you are familiar with the content and format of textbooks. The depth of information and the relationship and reference of that information to its primary sources vary widely from text to text. However, during the writing and publication process, college-level textbook manuscripts are generally reviewed by a large number of knowledgable scientists. Therefore, you can be reasonably confident that the information in textbooks is accurate. However, on critical or controversial points, it is always best to consult the primary sources and formulate your own opinions.

\section{Presenting Science to a Broader Audience: Popular Press, News, Television, etc.}

Much of the lay person's knowledge of science comes from the news and popular science media. Such sources tend to popularize science by selecting those stories deemed to be of the greatest interest to their intended audience and present information in a way that captures the audience's attention. Some science journalists have a strong academic background in science and are proficient at presenting science in an accurate way. Many 
others lack the background to present scientific studies with a focus on the actual hypotheses and conclusions. They tend to rely instead on the more speculative aspects of studies. The bias of the authors or those they interview is often apparent. As a result, you must be particularly cautious when presenting information from popular science and news sources. Seek to consult the primary sources of the information whenever possible.

- Please complete Items 1 and 2 on the Literature Reference Worksheet.

\section{Finding and Accessing Information}

You will be instructed on this topic by Darlene Brooks, Rhodes' Electronic Resources Librarian during the second week of lab. For finding primary literature on medically related topics or published in medically related journals, search PubMed. For primary literature on other topics in biology, try CSA (Cambridge Scientific Abstracts) and Ingenta (formerly CARL/Uncover and Reveal). These services provide abstracts to printpublished works and, in some cases, access to full text of the articles online.

- Please complete Item 3 on the Literature Reference Worksheet.

\section{Evaluating the Validity of Information}

How confident can you be that the information you read or hear is valid and unbiased? The paragraphs above indicate the level of review that each type of printed information undergoes. If you still don't have a good sense of which of those sources is more or less reliable, please read over that text again and/or talk to your professor.

It is increasingly common for us to use the Internet as a source of information. Certainly, Web pages exist that follow the print-based conventions mentioned above. However, for better or worse, virtually anyone can publish virtually anything on the Web without review or editing. Scientific information may be presented by scientists themselves without having it reviewed by peers, by government agencies seeking to inform the public, by corporations with a vested interest in promoting their products, by non-profit organizations serving their particular missions, or by individuals exercising their freedom of speech. Some information from these sources is scientifically accurate; some is not. But how can you judge? The following table outlines specific criteria to consider (Kapoun, 1998; reproduced by permission).

\begin{tabular}{|c||c|}
\hline \multicolumn{2}{|c|}{ Five criteria for evaluating Web pages } \\
\hline \hline Evaluation of Web documents & How to interpret the basics \\
\hline 1. Accuracy of Web Documents & Accuracy \\
\hline
\end{tabular}




\begin{tabular}{|c|c|}
\hline $\begin{array}{l}\text { - Who wrote the page and can you } \\
\text { contact him or her? } \\
\text { - What is the purpose of the } \\
\text { document and why was it } \\
\text { produced? } \\
\text { - Is this person qualified to write this } \\
\text { document? }\end{array}$ & $\begin{array}{l}\text { - Make sure author provides e-mail } \\
\text { or a contact address/phone number. } \\
\text { - Know the distinction between } \\
\text { author and Webmaster. }\end{array}$ \\
\hline $\begin{array}{l}\text { 2. Authority of Web Documents } \\
\text { - Who published the document and } \\
\text { is it separate from the } \\
\text { "Webmaster?" } \\
\text { - Check the domain of the document, } \\
\text { what institution publishes this } \\
\text { document? < qualifications? her or } \\
\text { his list publisher the }>\end{array}$ & $\begin{array}{l}\text { Authority } \\
\begin{array}{l}\text { - What credentials are listed for the } \\
\text { author(s)? } \\
\text { - Where is the document published? } \\
\text { Check URL domain. }\end{array}\end{array}$ \\
\hline $\begin{array}{l}\text { 3. Objectivity of Web Documents } \\
\text { - What goals/objectives does this } \\
\text { page meet? } \\
\text { - How detailed is the information? } \\
\text { - What opinions (if any) are } \\
\text { expressed by the author? }\end{array}$ & $\begin{array}{l}\text { Objectivity } \\
\text { - Determine if page is a mask for } \\
\text { advertising; if so information might } \\
\text { be biased. } \\
\text { - View any Web page as you would } \\
\text { an infomercial on television. Ask } \\
\text { yourself why was this written and } \\
\text { for whom? }\end{array}$ \\
\hline $\begin{array}{l}\text { 4. Currency of Web Documents } \\
\begin{array}{l}\text { - When was it produced? } \\
\text { - When was it updated? } \\
\text { - How up-to-date are the links (if } \\
\text { any)? }\end{array}\end{array}$ & $\begin{array}{l}\text { Currency } \\
\text { - How many dead links are on the } \\
\text { page? } \\
\text { - Are the links current or updated? } \\
\text { - Is the information outdated? }\end{array}$ \\
\hline $\begin{array}{l}\text { 5. Coverage of the Web Documents } \\
\text { - Are the links (if any) evaluated and } \\
\text { do they complement the documents } \\
\text { theme? } \\
\text { - Is it all images or a balance of text } \\
\text { and images? }\end{array}$ & $\begin{array}{l}\text { Coverage } \\
\text { - If page requires special software to } \\
\text { view the information, how much } \\
\text { are you missing if you don't have } \\
\text { the software? } \\
\text { - Is it free or is there a fee to obtain }\end{array}$ \\
\hline
\end{tabular}




\begin{tabular}{|c|c|}
\hline $\begin{array}{l}\text { Is the information presented cited } \\
\text { correctly? }\end{array}$ & $\begin{array}{l}\text { the information? } \\
\text { Is there an option for text only, or } \\
\text { frames, or a suggested browser for } \\
\text { better viewing? }\end{array}$ \\
\hline \multicolumn{2}{|l|}{ Putting it all together } \\
\hline \multicolumn{2}{|c|}{$\begin{array}{l}\text { - Accuracy. If the page lists the author and institution that published the page and } \\
\text { provides a way of contacting him/her, and ... } \\
\text { Authority. If the page lists the author credentials and its domain is preferred } \\
\text { (.edu, .gov, .org, or .net), and ... } \\
\text { Objectivity. If the page provides accurate information with limited advertising } \\
\text { and it is objective in presenting the information, and ... } \\
\text { Currency. If the page is current and updated regularly (as stated on the page) } \\
\text { and the links (if any) are also up-to-date, and ... } \\
\text { Coverage. If information can be viewed properly--not limited to fees, browser } \\
\text { technology, or software requirement, then ... }\end{array}$} \\
\hline $\begin{array}{l}\text {...you may have a higher quality } \\
\text { research! }\end{array}$ & age that could be of value to your \\
\hline
\end{tabular}

- Please complete Item 4 on the Literature Reference Worksheet.

[To find some interesting and often entertaining perspectives on biased science reporting (perspectives which are generally biased themselves), you may choose to enter "junk science" in to a Google search and browse.]

\section{Analyzing and Presenting Information: Avoiding Plagiarism}

The term "plagiarism" is defined as cheating; specifically, it is the act of using another person's words or ideas without documenting them properly (footnotes, bibliography, etc.). This includes, without limitation, using information from any source without proper reference, getting ideas or words from a classmate's paper, failure to properly punctuate direct quotes, and obtaining a paper from someone else [emphasis added]. Ignorance is not an excuse for these violations. It is the student's responsibility to consult the professor, an Honor Council member, or writing handbooks for procedure for properly acknowledging sources. (Honor Council Home Page, 2000)

When you complete a paper, lab report, or presentation for class, your composition will contain a lot of information (data, factual statements) and interpretations. The information and interpretations come from either your work and thinking, or they come from something you've read (e.g. in a book, paper, Web site. etc.) or heard (e.g. in a 
lecture). It is assumed that statements without citations are your own. Therefore, if information or interpretations you read about or heard are stated in your paper without the correct citation, you will have committed plagiarism.

\section{How to provide proper reference citations in the body of your paper}

\section{Take Notes}

As you research the literature, keep a journal with detailed notes on the information and citations you find. If you are taking notes from a book or Web site in preparation for writing your paper, put citations down on the paper with the information you have collected. If you copy something word-for-word (verbatim) from your reference, put it in quotes so you remember that it is a direct quote. As you write your paper, include the citations along with the information. Without keeping detailed notes and citation information in your journal you might start thinking the ideas of others are your own after you have read them and thought about them so much.

Put citations with each statement you write (if it isn't your original thought/data) If a paragraph contains multiple points of information that you have brought together from different sources, put a reference in or after every sentence or statement. Try different ways of inserting the citation, for example:

Birds with oil in their feather lose $20 \%$ of their body heat (Smith, 2001).

Smith (2001) found that birds with oil in their feathers lose $20 \%$ of their body heat.

Although migrating birds suffered no ill effects (Johnson, 1999), the resident birds collected by Smith (2001) showed a substantial loss of body heat because of the oil in their feathers.

What if you have a whole paragraph from one source? Do you still have to cite a reference in or after every sentence? No, you don't need to put the reference citation in every sentence (that would look bad and would be frustrating to read). But, you must construct your paragraph carefully so that it is clear all the information came from that source. Consider the following paragraph.

In a recent survey of oil-polluted lakes, Smith (2001) found that resident birds had substantial amounts of oil caught in their feathers. Using thermal conductance tests, he recorded that the birds with oil lost $20 \%$ of their body heat within 30 minutes. This was significantly more heat lost than in the control (uncontaminated) birds, which only lost $5 \%$ in the same time period. These results indicate that birds in oil-polluted lakes would have higher caloric demands because of lost body heat, and would be expected to be feeding more often.

In the paragraph above only the first sentence contains the citation. Are the remaining three sentences from Smith's paper? The second two sentences are clearly from Smith's paper, even though his reference is not cited in the lines. In sentence two, the phrase "he 
recorded" shows the reader that the author is still discussing Smith's paper. Sentence 3 is also from Smith's paper because it is describing the control to his experiment. However, there is nothing in the last sentence that indicates it came from Smith's paper. To your professor, the absence of a citation in the last sentence would indicate that it is your interpretation based on what you learned from Smith's 2001 work. In fact, this sentence has two statements of interpretation: that the oil-covered birds have higher caloric demands because of lost body heat, and that these birds are hypothesized to be eating more often. If either of these ideas actually came from Smith's paper and were not your interpretations, technically you would be guilty of plagiarism.

- Please complete Item 5 on the Literature Reference Worksheet.

The example above may seem trivial, but it is important. When your professor reads your paper, he/she is looking specifically for statements such as this. If this is your original idea or interpretation, then it shows you have done an excellent job of gathering information from references and thinking about what it means. Such a high level of synthesis and understanding would likely warrant a higher grade. This is one example of why plagiarism is unacceptable; you would earn credit for someone else's work or idea. This example also shows why it is important to cite references carefully throughout all parts of a paper. If your professors see examples of sloppy citation, they may or may not formally accuse you of plagiarism, but they certainly won't know what parts of the paper are your original ideas. Your professors might assume that everything came from references and not credit you for your critical thinking skills. (Another important reason for citing references properly is that references provide verification for the reader. If you see an unusual or controversial idea with a citation from a rigorous primary literature article, you might have more confidence in its validity than if the citation shows the idea came from a child's 4 th grade class Web site.)

Another technique sometimes used to indicate all information in a paragraph comes from a single source is to cite the reference at the end of the paragraph, after the last period. If you do this, you must be very careful not to make errors in punctuation, and you should make sure that your professor is aware of the convention. (Not all faculty know about or use this method; a note attached to the paper indicating the method you used would be helpful.)

Finally, when in doubt, cite more rather than less! After your paper is written, read through each sentence and ask yourself, "is this my own idea or information?" If your answer is "no," then whose is it? That reference should be put in the statement.

\section{Avoid using direct quotes}

In most circumstances, there is no reason to copy someone else's words directly. In English papers, it is often done because the discipline centers on the fine craft of writing and is needed to show the eloquence of an author's words. In biology, a direct quote often signals that you didn't understand the source well enough to be able to rephrase it into your own words. However, a word or a phrase is sometimes so distinctive or perfect that there are no good alternatives. In that case, you must enclose all of the copied text in 
quotation marks and include a reference citation as usual. Another way to quote text, especially paragraphs and other long passages, is to indent the entire paragraph (a technique known as a block quote). For example, the first paragraph of this document is quoted from the Honor Council Home Page.

Students most often make mistakes with direct quotes when they are sloppy taking notes and neglect to put quotation marks around text that they have copied verbatim from a source. Those copied words then end up in the paper because the student forgets that he or she had copied the text instead of paraphrasing it. Remember, carelessness or ignorance is not an excuse. You will still have committed plagiarism, even if it was unintentional.

- Please complete Item 6 on the Literature Reference Worksheet.

Use an appropriate citation format

Each journal publishes its own Instructions to Authors document that outlines, among other things, the reference format to be used for papers submitted to that journal. For Summer Scholars, the format you are to use for papers and presentations is outlined in the Citation Guidelines. Study the examples carefully and follow them precisely.

- Please complete Items 7 and 8 on the Literature Reference Worksheet.

Follow copyright law

You will be instructed on copyright and fair use guidelines by Darlene Brooks, Electronic Resources Librarian. Generally, copyrighted text and images can be reproduced without permission from the copyright holder for one time use for educational purposes if it is restricted to class participants and if it is appropriately cited. Any reference librarian will be happy to address questions you have in this regard.

\section{Literature Cited}

Honor Council Home Page [web page] 2000. http://hc.rhodes.edu/constitution.htm. [Accessed 9 January 2002].

Kapoun, J. 1998. Teaching undergrads WEB evaluation: A guide for library instruction. In College and Research Libraries News. 59(7):522-523. 


\title{
Appendix 5: Citation Guidelines
}

\section{Guidelines for Literature Citation}

While there are many formats for citation used in the academic world, YOU MUST USE THE METHOD OF CITATION OUTLINED BELOW FOR ALL WORK IN THIS COURSE. Grades for any papers or presentations with improperly cited references will automatically be reduced by one letter grade.

When you use any information from a published source you must cite the reference with a parenthetical notation in the text next to the information and list it at the end in a "Literature Cited" section. Examples for books, journals and web sites are shown below. (Note that you must use quotation marks when you use a word-for-word, direct quote; however, you should strive to paraphrase in scientific writing unless a direct quotation is absolutely necessary. As always, evaluate web-based information carefully for accuracy before citing it.)

\section{How to cite IN the TEXT}

example sentences (see below for web references)

According to Smithe (1997), all biologists should learn about diversity.

"Understanding diversity is important for human survival" (Smithe, 1997, p. 7).

Tropical rainforests have very high diversity of insects (Wilson, 1994).

Fungi are more closely related to animals than animals are to plants (Wainright et al., 1993, cited in Ackbar \& Fay, 1998).

[Use this format if you have not seen the original article, but read about it in another reference. Put both the original article and the reference you read in the Literature Cited section.]

Although prairie voles appear monogamous, DNA paternity studies have shown that they do not practice sexual exclusivity (Carter \& Getz, 1993).

\section{How to format complete citation IN the LITERATURE CITED SECTION}

Example Literature Cited Section based on text above (see below for web citations).

\author{
$\underline{\text { Literature Cited }}$
}

Ackbar, I. \& H. Fay. 1998. Introductory Zoology. Boston: Mosby Press. 
Carter, S. C. \& L. L. Getz. 1993. Monogamy in voles. In Sexual Selection in Prairie Voles: 355-385. Who, R. \& N. Fiction (Eds). New York: Freeman Co.

Smithe, I. M. 1997. A Guide to Introductory Biology in the 1990's. (2 ${ }^{\text {nd }}$ edn). Athens, Georgia: McGraw-Hill.

Wainright, P. O., G. Hincke, M. L. Sogin, \& S. K Stickel. 1993. Monophyletic origins of the metazoa: an evolutionary link with fungi. Science 260:340-342.

Wilson, R. 1994. Diversity in tropical ecosystems. J. Tropical Bio. 20:5-18.

[In these examples, the first and third are books, the second refers to a chapter or article in a book, and the last two refer to journal articles. For journal articles, the format is Journal Name vol:inclusive page numbers; thus, Wilson (1994) is published in the Journal of Tropical Biology, volume 20, pages 5-18.]

\section{How to cite Web sites in the text}

In the body of your paper, you should reference the information with the name of the author of the web site or the name of the organization, and the date the site was last modified. If such information is not obvious, select "Page Info" under the View menu if you are using Netscape (or the comparable function if you use another browser). If you discover that the source and date modified are unknown, cite the title of the page and the date that you accessed it.

example sentences:

Carbon dioxide, methane and nitrous oxide are the major greenhouse gases produced in the United States (Watchley, 1997).

The years 1997,1995 , and 1990 were the three warmest in over a thousand years (GW News Flash, 1998).

The months of January to October of 1998 make up the warmest period ever recorded (The EPA Global Warming Site, 1998)

\section{How to format Web site citations in the Literature cited section}

To put the Web references in your Literature Cited section, you'll need to enter as much of the following information as you can find:

Author(s). Title of Article. [web page] date of publication or date last modified; the web address (i.e.the URL). [Date you accessed it]. 
Examples of fictitious web site citations for the text above:

[Note that some of these do not have all of the information, but all include the URL so that someone reading your paper could visit the same site.]

\section{$\underline{\text { Literature Cited }}$}

GW News Flash [web page]

http://www2.msstate.edu/ krreddy/glowar/news.html. [accessed 12 Dec 1998]

The EPA Global Warming Site [web page] 27 April 1998;

http://www.epa.gov/globalwarming/news/index.html. [Accessed 15 Dec 1998].

Watchley, P. T. Greenhouse gases in the U.S. [web page] 12 Nov 1997;

http://gases.all.around.us.rhodes.edu. [Accessed 30 July 1998]. 


\section{Appendix 6: Process Diversity Paper Instructions Process Diversity Paper and Journal}

\section{Paper}

For this written assignment, you will work in groups of three to study how different animals carry out a particular process in different ways. Your choices must emphasize the great diversity of approaches to the process among three animals from different phyla (Kingdom Animalia only). Each group of three students will be assigned one of the following processes in class.

1. Reproductive strategy

2. Locomotion

3. Predator avoidance

4. Feeding

5. Gas exchange

6. Medical uses

7. Commercial uses (excluding medicine and food)

8. Sensory perception (sound, light, gravity, etc.)

The group paper must be five pages in length and must consist of the following.

Page one: a brief Introduction

Provide a title, list the names of the students in the group and the animal each one studied, and sign to pledge the honor code. State the process and how your group interprets or defines the process. All three group members should contribute to this paragraph.

Pages two, three and four: Descriptions of Process, one page per animal Each member of the group of three will write one of these sections describing how a particular animal performs the process as your group interprets it. Each member is to focus on only one species and one specific example of the process within that species. Each student must write his/her own page on the process for his/her selected animal, but the group must confer at the beginning to ensure that group members are selecting a diversity of animals. Be sure to explain in depth how an animal's anatomy/physiology allows it to carry out its function. At the start of each section you should clearly name the animal to be discussed and its taxonomic position. Humans cannot be used for any examples. Each section must have its own appropriate references with in-text citations. See the Appendix in the lab manual for the appropriate format. You must use at least one online reference and one print-based reference.

Page five: Literature Cited

This page must list alphabetically the references that were used in the introduction and by each group member in his/her section. Since it combines everyone's references, all three group members should contribute to this. See the Appendix in the laboratory manual for the appropriate format. You must adhere to this format for references throughout this course. If you have any questions about the format, ask your professor. Errors in any reference formats will result in point deductions from the grades of all group members, so 
check each other's work.

You may use your lab manual and text to assist you in this assignment, but each member of the group is required to use at least one online reference and one print-based scientific reference as well. Dictionaries, encyclopedias, "facts on file," and the like do not count as scientific references. Look for information in text books, scholarly books, and journal articles. Furthermore, you should be confident in the accuracy of any information you cite from a web site. To assist in these matters, complete the Literature Reference Worksheet.

\section{Journal}

Purchase a bound composition book for use as a journal in this course. Use this journal as a place to informally track your literature research and, later in the semester, your laboratory research project. For this assignment and any others requiring literature research, as you find information in various sources, take notes and paraphrase the information or, if you write it verbatum, place quotes around the text, and write the full citation information. When you then draft your paper, refer to the notes in your journal and select the information and references you wish to include.

You must turn in your journal with this assignment. You will receive it back and you may use it for other assignments. You will also use your journal to keep notes on your independent experiment and will turn in the journal with your research report at the end of the semester. Details of what to include in your journal for that project will be forthcoming.

\section{Grading}

This assignment is worth 15 points. The points will be apportioned as follows: 5 points content (diversity of organisms and mechanisms, depth of discussion), 5 points style (clarity, organization, grammar, spelling), 5 points references and journal. 


\section{Appendix 7: Development Experiment Report Guidelines} DEVELOPMENT EXPERIMENT REPORT

Instructions - One report is to be submitted by each group. Label each section of the report according to the following underlined headings and include the suggested information.

Introduction

Give some background about malathion and its known effects on amphibian development. Be sure to cite articles properly in your text and include the full citation at the end of your paper. [Biology of Amphibians (Duellman \& Trueb, 1994) and a folder with some papers on malathion are on reserve at the library. Please DO NOT check books out of the library.]

Restate the prediction that you turned in last week. On pages 12-16 of Biology (Starr \& Taggart, 2001) the term "prediction" is used to mean a specific hypothesis such as your own that predicts what you will observe or measure.

Methods

State how you measured development to test your hypothesis (e.g. what stage predominates after $x$ hours, rate of growth)

$\underline{\text { Results }}$

Get a photocopy of the data from another group. Be sure to name the other group in your paper and turn in both your data sheets and the photocopied sheets.

Graph data from both groups. Use your graph to support or refute your prediction by comparing rates or final stages.

Discussion [interpretation of results (use references - see Introduction above)]:

What is the significance of the results? There are several possibilities for discussion. You do not need to cover all of these topics. If your data support your prediction, what could be the mechanism by which malathion does this? What might be the ecological, developmental, or physiological significance of malathion's effect? Or its lack of effect if you refuted your prediction. Note on page 12 of Biology (Starr \& Taggart, 2001) that a "specific hypothesis" or "prediction" may be rejected even if the general hypothesis is not. What revised prediction could you make if you refuted this one? If the hypothesis is refuted, what revised hypothesis could be stated?

Discuss any important observations (e.g. can you account for variability in growth rates, high mortality, etc.). 
Literature Cited - use format outlined in Literature Reference exercise.

Remember, this is a group effort. It is your responsibility to make sure that you do your share. When you turn in your write-up each person will complete an evaluation of everyone's contributions to the group.

Grading - This assignment is worth 15 points. You will be evaluated based on the following breakdown.

Introduction

Background information on malathion and effects of development ( $2 \mathrm{pts})$ Use of references to support background (1 pt)

Statement of hypothesis $(1 \mathrm{pt})$

$\underline{\text { Methods }}$

Statement of how development was measured and compared (1 pt)

$\underline{\text { Results }}$

Quality of group's data sheet (1 pt)

Graphing of data from both groups ( 2 pts)

$\underline{\text { Discussion }}$

Use graph to support or refute hypothesis (2 pts)

Interpretation of results ( $2 \mathrm{pts}$ )

Discussion of important observations (changing rate, mortality, variability, etc.)

(1 pt)

Support of interpretation with references (1 pt)

Literature cited - appropriate reference format ( $1 \mathrm{pt})$ 


\section{Appendix 8: Renal Function Experiment Worksheet}

NAME

\section{Renal Function Experiment Workheet \\ 10 points}

1. Draw $\mathrm{X}$ and $\mathrm{Y}$ axes below and graph the class percent change in urine volume for either the water or tomato juice treatments. (5 pts)

2. Diagram and describe the mechanism by which the brain and kidneys control homeostasis in the blood using $\mathrm{ADH}$. Use the information in your diagram to explain the results you graphed above (5 pts). 


\section{Appendix 9: Behavior Experiment Report Guidelines}

\section{Instructions for a Report on an Animal Behavior Experiment}

In lab, you will conduct two defined experiments on crayfish behavior. For the third experiment, you will design and test your own hypothesis and report on your findings. For example, if you observed a preference for one of the two substrates, sand or charcoal, you should have asked yourself, "What were the cues used by the crayfish?" Was color involved? What role did texture play? As a group, you must develop and then present a hypothesis to your instructor. Devise and perform an experiment in lab to test this hypothesis.

Before the lab day is over, your group must submit a brief report that includes the following:

1. Statement of hypothesis tested

2. Very brief statement of methods

3. Your data, including statistical analysis where appropriate

4. Conclusion: do your data support or refute the hypothesis, and your interpretation. 


\section{Appendix 10: Proposal Preparation Guidelines}

\section{Instructions for the Independent Group Research Project Proposal}

For your group independent project, you may choose to monitor under experimental conditions one or more of the physiological variables for which the MacLab workstations are equipped. Alternatively, you may use the crayfish in the lab to study various aspects of animal behavior.

Your group will need to select one of these two areas of study (or another if approved) and propose a testable hypothesis and plan of action. At the designated time, your group will be required to submit two copies of a typed proposal to your professor, who will review it during lab. If your professor recommends changes in the proposal, you will need to revise it and resubmit the two new copies before the end of lab. For this reason you are urged to write your proposal using one of the campus computers, save it to the student server so that any revisions can be made quickly and easily while in lab.

The proposal must include the following four sections. Be sure to list them in order with the appropriate headings.

1. Group Members - A list of the names and phone numbers of each group member

2. Hypothesis - A statement of your hypothesis and reasoning (References are not necessary here, but use of references is a good idea while constructing your hypothesis, and they will be required in your presentation.)

3. Methods - A brief description of your protocol. This must include

1. the sample size

2. briefly what you will be doing (don't repeat procedures written in this or other lab handouts, simply refer to them and explain proposed procedures that might differ from these or be seen as refinements)

3. how you will analyze the results, including appropriate statistical tests to be used

4. Equipment List - A complete list of all equipment you will require This should not be part of your final presentation, but it is necessary now to allow us to assemble basic lab materials for you. 


\section{Appendix 11: Scientific Presentation Guidelines}

\section{Guidelines for Research Presentations}

While preparing your presentation you need to keep a number of criteria in mind. First you should approach the construction of your presentation seriously. "Cute" formats such as unnecessary pictures and drawings, excessive or distracting transitions, and showy color combinations should be avoided. If you do not present your work in a serious fashion, then nobody will take you or your conclusions seriously. Keep text to a minimum and make sure that the text is easily read from anywhere in the lab. All presentations should contain the following components:

\section{TITLE SLIDE}

Use a short, yet descriptive title. Include the names of the people in your group and your laboratory section.

\section{INTRODUCTION}

The introduction provides a reader with a general background to the scientific problem and the rationale used to derive the hypothesis investigated. Background information must have appropriate references (include citations on the slide). This section should clearly pose the basic question or hypothesis.

\section{METHODS}

This section describes the methods that you used to investigate the problem. The audience should clearly understand exactly what you did in your experiment. Authors frequently cite a paper that describes a particular technique in this section to reduce the length of the description. Remember to be brief yet thorough. Do NOT include a list of materials.

\section{RESULTS}

The results section is the meat of your presentation. Most of you (depending on your project) will first need to "reduce" your data. Reducing data is converting the numerous individual measurements into a couple of simple descriptive values, such as a mean and standard error. You will also need to use some type of statistical test to determine if your treatment had an effect or if your null hypothesis should be rejected. How you reduce your data and what type of test you use depend on your project and the data you've collected. For example, if you did a crayfish project in which you compared observed to predicted behaviors, you will probably need to use some type of X2 test. You should check with your professor to make sure that the test you have chosen in the correct one for your data. If you did one of the physiological investigations, most likely you will have data that can be presented as means with standard errors, but you will then need to perform statistical tests to determine if differences exist between those means. For example, is the mean systolic blood pressure of athletes different from the mean systolic blood pressure of couch potatoes? Appendix IV: Introduction to Elementary Statistics will help you choose the appropriate test to analyze your data, and guide you through the mechanics of the analysis. The type of statistic you use is determined by the characteristics of your study, such as whether you collected data twice from the same group of people (i.e. before and after eating potato chips) or from two different groups 
(weightlifters vs. sprinters). If the statistics described in the Introduction to Elementary Statistics do not seem to fit your data, speak to your professor. Your project may require an entirely different type of analysis, such as a X2 test.

Whether you calculate means or not, the data should be presented as a table or a graph. Tabular presentations of data typically are used when you feel it is important to present the viewer with a comparison of exact numbers. Usually, the table will present the means and standard errors of the data. Graphs are used when you wish to show a general trend or desire to graphically illustrate a relationship between two or more variables. Most graphs will also show the means and standard errors. Try to keep from presenting the same data in both a table and a graph, and any table or graph in your presentation should have a purpose (i.e. be there to make a point). Make your graphs simple and easy to understand, and be sure to label them completely.

There are some common protocols practiced by a number of scientific societies when constructing tables and graphs. First, all types of data presentation should be numbered in the order with which they are discussed in the text of the paper. Thus Table 1 should be the first discussed and Table 7 the last of seven discussed. Graphs and diagrams are referred to as figures (i.e. graph 3 would be called Figure 3). All of the tables and figures should have a title and a brief legend. A good title should summarize in one sentence what the presentation is showing. The purpose of the legend is to briefly explain the major point of the data, and what the various symbols on the figure represent.

Besides the data, the results section should include a brief description of the data presented including the pertinent points you are trying to make with each presentation. However, you should avoid making any sort of conclusions about the data with regard to the overall question you are trying to answer. Thus, it would be acceptable to say "Figure 1 shows that treatment A almost doubled the ratio observed in the control...", but it would not be acceptable to include "... which means that the answer to the question posed in this study is that treatment $A$ affects the organism and changes its ability to perform the physiological act in question." Save the latter statement for the Discussion.

\section{DISCUSSION}

The discussion section is your opportunity to review the findings of your studies and make conclusions based on the data. Take care that you not over-generalize your conclusions. Be specific as to what questions your data address. After you have established the answers provided by your data set you can go on and generalize how these data may be important in a broader sense. This might include proposing your own model or your own opinion of the importance of vital capacity to athletic performance, for example. You may want to conclude with some remarks on the limitations of your experiments as well as ideas on how you might extend these studies.

\section{REFERENCES AND LITERATURE CITED}

Three criteria are important: 1) The quality of the references you use, 2)-how you cite the work within the text, and 3) how the literature cited section is constructed. 
Quality of References

Our expectation is that your presentation should attain a depth of understanding greater than what is written in your biology textbook or what you have learned in lecture. To attain that depth of understanding requires that you read, learn, and use information from at least two good, sophisticated, published scientific references (remember, web sites are often not "published"). We define a good scientific reference as a journal article or book that has information in greater depth than your textbook. It is NOT an encyclopedia or dictionary, and it is NOT a popular magazine (i.e., TIME). With a rare exception, the more recent the reference, the better. For example, do not use articles from before the 1950 's unless they are landmark papers referenced in all of your sources. Presentations that have multiple scientific references and make good use of the information from those references will be given higher evaluations.

$\underline{\text { How You Cite the Work }- \text { See Citation Guidelines }}$ 


\section{Appendix 12: Ecology Experiment Worksheet}

\section{Ecology Worksheet}

Name Lab day $/$

prof.

Pledge (You may work with your lab partner to generate the graphs, but the remainder of this worksheet must be done on your own.)

1. Staple your three graphs of the class data to this sheet.

2. Before you looked at the r values calculated for your class data, did you "feel" you could reject any of your null hypotheses?

3. Given the $r$ values for these data, are you able to reject any of the null hypotheses? If so, which one(s)?

4. Which of the three measurements (H', number of species, or number of animals) do you think provides a more meaningful indicator of diversity? Explain. 